Doi: https://doi.org/10.31578/jebs.v6i2.231

\title{
The Effects of Culture on Learning Styles: The Sample of Ondokuz Mayıs University*
}

Fatih Diken*

Nevin Özdemir**

\begin{abstract}
This study examines the effect of culture on learning styles. The study sample consisted of undergraduate and graduate students, most of whom are foreign nationals, studying in different departments of Ondokuz Mayıs University in Samsun, Turkey. Based on the experiential learning theory (ELT), Kolb's Learning Styles Inventory (KLSI) was used as a data collection tool to define individual learning styles. By examining previous studies such as the Global Leadership and Organizational Effectiveness (GLOBE), the study focused on categorizing cultural differences. 193 participants from 35 different nationalities were included in one of three cultural clusters (The Middle East, Africa, and Central Asia). In the first part of the study, the dominant learning styles of each cultural cluster were evaluated based on Kolb's traditional 4 learning styles (diverging, converging, assimilating, and accommodating) and the new 9 learning styles (experiencing, imagining, reflecting, analysing, thinking, deciding, acting, balancing) defined in KLSI 3.2 and KLSI 4. It was analysed whether there was a statistically significant difference in the dominant learning styles among the cultural clusters. The results of the analysis showed that there was no significant difference among the cultural clusters according to 4 learning style classifications, whereas there were significant differences among the cultural clusters according to Kolb's 9 learning style classifications. In the second part of the study, it was evaluated whether there was a significant difference among the cultural clusters according to the modes of grasping experience - concrete experience (CE) and abstract conceptualization (AC) - and two dialectically related modes of transforming experience-reflective observation defined in the ELT model.
\end{abstract}

Keywords: learning style, Kolb learning style inventory (KLSI), culture, cultural dimensions, cultural clusters, higher education

\section{Introduction}

The export of higher education services has become an important financial resource for most countries. Developing countries such as Turkey have also seen an increase in the number of foreign students, as well as developed ones such as the USA, United Kingdom, France, Germany. Many universities started tapping into international markets for higher education to increase the income from international students by offering distance learning programs, and collaborative programs with local universities abroad, or by opening their branches in other countries (Holtbrügge \& Mohr, 2010). Consequently, there has been a remarkable increase in the number of foreign students enrolled at universities in the last twenty years, and the increase in the number of foreign students is likely to continue in the coming years. Turkey is one of these countries, and it has been observed that the

*The data used in this article were obtained from the postgraduate thesis of the first author, and This study was supported by the Scientific Research Projects commission of Ondokuz Mayıs University, (Project number: PYO:MUH:1905.15.001).

* Cumhuriyet University, Department of Turkish and Social Studies Education, the Ph.D. student on Social Studies Education, Sivas, Turkey, https://orcid.org/0000-0002-6108-3570.

** Assoc. Prof., Education Faculty, Ondokuz Mayıs University, Samsun, https://orcid.org/0000-0001-9408-3238

Corresponding Email: nevino@omu.edu.tr ; nvnozdmr@hotmail.com 
number of foreign students in universities in Turkey has increased significantly in recent years. According to the statistics of Turkey Higher Education Information Management System (THEIMS) (YÖBS,2020), there were a total of 107,947 foreign students enrolled at universities in Turkey, in the 2016-2017 academic year in which this study was carried out. This number reached 154,446 increasing approximately by 50\% in the 2018-2019 academic year. Currently, Turkey offers higher education services to students from more than 140 countries, most of them are Central Asian, Middle Eastern, and African ones. Considering the attempts to attract students from other countries, it can be predicted that the cultural heterogeneity of university students will continue to increase in the coming years. Therefore, to ensure that all students achieve their learning goals, it is important to include practices such as revising the learning support services of universities, changes in curriculum, and adjustment of teaching strategies. Some studies in the field of learning management draw attention to cultural differences in learning styles (for example, Abramson, Keating, \& Lane, 1996); therefore, it is important to be aware of the learning styles of students from different cultural backgrounds. According to Given (1996), considering individual learning styles has the potential to contribute a statistically significant improvement in the development of positive attitudes towards teaching, the increased tolerance to cognitive diversity, and a statistically significant increase in academic achievement. The issue of the impact of cultural differences on learning has been becoming more important in higher education.

Learning is one of the most universal of human activities. Culture is defined as shared motives, values, identities, and interpretations or meanings of significant events that result from common experiences of members of collectives that are transmitted across generations" (House et al., 2004, p. 15), and the relationship between learning and culture has been the focus of attention of researchers from different disciplines. For example, in his book The Geography of Thought, Richard Nisbett, cognitive, cultural psychologist, explained how his work with a Chinese student challenged and changed his lifelong universal cognitive view that all human groups perceive and reason in the same way (Joy \& Kolb, 2009). According to the Chinese student, westerners live in a simpler and more stable world; they focus on remarkable objects or people instead of the bigger picture, and they think they can control events because they know the rules that govern the behaviour of objects. In contrast, the Chinese believe in the relationships among beings, the importance of context, and constant change (Nisbett, 2004). Other culture researchers support the view that culture might be related to the development of learning styles, and culture acts as a powerful socialization tool (Barmeyer, 2004). Furthermore, the differences in cultural socialization tend to produce different learning styles or affect individuals' learning preferences (Yamazaki, 2005). For this, some researchers also had tried to find empirical evidence to support learning style differences based on cultural background (Joy \& Kolb, 2009). Thus, in a series of comparative studies using different measurement tools, it had been reported that the culture had a significant effect on some of the demographic variables in learning style scales (Auyeung \& Sands, 1996; Barmeyer, 2004; Boland et al., 2011; Dunn et al., 1990; Heffernan et al., 2010; Holtbrügge \& Mohr, 2010; House et al., 2004; Joy \& Kolb, 2009; Yamazaki, 2005).

It is noteworthy that studies focusing on the relationship between culture and learning styles have similar or different aspects, especially in terms of measurement tools and study samples. For example, Allinson and Hayes (2000) examined differences in learning styles of managers from six nations and management students from five nations completed the Cognitive Style Index. In another study, a comparison was made between the learning styles of Chinese and European managers by using the Myers-Briggs Type Indicator (Furnham \& Stringfield, 1993). Vermunt's Inventory of Learning Styles (ILS) was also used in some international studies on learning styles (Marambe et. al., 2012; Martínez-Fernández, \& Vermunt, 2015). The Solomon-Felder Index of Learning Styles was used to determine the learning styles of Chinese and Australian students (Heffernan et al., 2010), and also to compare the learning styles of Middle Eastern and American students (Zualkernan et al., 2006). In another study, the Learning Style Inventory (LSI) (Dunn, Dunn, \& Price, 1985) was used to compare the learning styles of primary-school-age American students from four different ethnicities (Dunn et al., 1990). However, it is noteworthy that the studies using the Learning Styles 
Inventory (LSI) developed by David Kolb were predominant among a series of studies focusing on cultural differences in learning styles by using different measurement tools such as these: for example, Auyeung and Sands (1996), Barmeyer (2004), Boland et al. (2011), Budeva et al. (2012), Çelikler (2020), Healey et al. (2005), Jaju et al. (2002), Maldonado-Torres (2011), Özdemir (2015), and Pokharel (2013).

In Turkey's educational science literature, currently, few studies are dealing with the relationship between culture and learning or comparing the learning styles of Turkish students with those from other countries. One of the pioneers of these studies was a postgraduate thesis (Hoppe, 1990). In that study, there were participants from 19 countries also including Turkey, and a questionnaire form containing Hofstede's Value Assessment Module and Kolb's Learning Styles Inventory was applied, which was sent via postal service to the participants between 1983 and 1984 years. Another study related to the learning styles was conducted by using a semi-structured interview method with 5 students, 3 of whom were Turkish, and 2 of whom were American citizens, studying at Midwestern University in America (Cagiltay \& Bichelmeyer, 2000). Also, in Kutay's (2006) study, the learning styles of Turkish and American undergraduate and graduate students from American universities were compared. Some studies related to the intercultural learning style were carried out with Turkish, Arab, Cypriot (Gündüz \& Özcan, 2010), Turkish and Taiwanese (Berberoglu \& Hei, 2003), and Turkish and Bosnia-Herzegovina (Obralic \& Akbarov, 2012) undergraduates. Furthermore, Özdemir (2015) compared the learning styles of students in geography departments of different universities in Turkey with the ones of Western geography undergraduates in the study of Healey et al. (2005). However, it was determined that there was no intercultural study in the literature on learning styles of foreign students studying at universities in Turkey.

Turkey is a country inhabited by people from many different cultures and ethnic groups as a result of its geographical location and historical background. In recent years, many refugees have immigrated to Turkey from neighboring countries due to reasons such as political instability or war in their countries. Educational services for those who want to study in Turkish schools and those who prefer to settle in Turkey are also provided besides numerous services such as shelter and health. Also, the number of students who have come to study in the universities in Turkey especially from Africa, the Middle East, Central Asia, and the Far East countries has been increasing recently. For this reason, it is essential to develop our understanding of the learning approaches of students from different cultures. In this regard, this study based on Kolb's 4 learning styles (diverging, assimilating, converging, and accommodating) and Kolb's 9 learning styles (experiencing, imagining, reflecting, analysing, thinking, deciding, acting, initiating, and balancing) was focused on whether there were any differences between the learning styles and culture in the sample of Ondokuz Mayıs University (OMU). The issues related to the study have been organized as follows:

1. According to the respondents' cultural clusters (Sub-Saharan African, Central Asian, and the Middle East):

2. What is the distribution of their preferred learning styles (according to Kolb's four- and nine-component classifications)?

3. Is there a significant difference in the learning styles?

4. Is there a significant difference based on learning modes (concrete experience, abstract conceptualization, reflective observation, and active experience) defined in Kolb's Experiential Learning Theory?

5. Is there a significant difference between the scores of the knowledge perception (abstract conceptualization-concrete experience) and information processing (active experience-reflective observation) dimensions of the experiential learning cycle? 


\section{Methodology}

\subsection{Procedure}

The current study was conducted based on learning styles, learning modes, information perception, and information processing methods defined in Kolb's Experiential Learning Theory (see for these; Kolb, 1984, Kolb \& Kolb, 2005; Kolb \& Kolb, 2006; Kolb \& Kolb, 2013). It was a quantitative case study in the survey model. The study sample consisted of 193 students from 35 different countries studying at different departments of OMU in the 2016-2017 academic year. Based on the study of Joy and Kolb (2009), we tried to create cultural clusters similar to the ones in the GLOBE study (House et al., 2004) considering the nationalities of the undergraduates in the study sample. However, students from all cultural clusters in the GLOBE's study could not be included in the study sample due to such reasons that the study sample was limited to the students who enrolled at OMU, and foreign ones having enough Turkish or English language proficiency to answer the measurement tool. Besides, the students from different countries, not including in the GLOBE study, also participated in the study. Therefore, the students from Kyrgyzstan $(n=4)$, Uzbekistan ( $n=2)$, and Turkmenistan ( $n=11)$ were included in the Central Asian cluster considering such criteria as geographical region, historical ties, ethnic origin, religion, and socio-economic structure. Kazakhstan was in the Eastern European cluster of the GLOBE study. However, it was decided that it would be more appropriate to include the 5 Kazakh students in the Central Asian cluster because they reported that they were ethnically Uzbek and came from a city close to the Kazakhstan/Uzbekistan border. Azerbaijani students $(n=5)$ were also included in this group. As seen in Table 1, the Central Asia group was formed with 31 students from 5 countries. In the GLOBE study, Turkey, Kuwait, Egypt, Morocco, and Qatar were included in the Middle East cluster. The Middle Eastern cluster of this study was composed of 91 students whose nationalities were Turkey $(n=24)$, Palestine $(n=6)$, Syria $(n=32)$, Egypt $(n=7)$, Yemen $(n=1)$, Iraq $(n=5)$, Morocco $(n=3)$, Algeria $(n=1)$, and İran $(n=12)$. İran was in the Southeast Asian cluster of the GLOBE study. However, Iranian students who participated in the study were included in the Middle East cluster, because they reported that they came from the province of Ardabil in the north of Iran close to the border with Turkey. As in the GLOBE study, Zimbabwe, Namibia, Zambia, Nigeria, and South Africa were included in the Sub-Saharan Africa group, and this cluster consisted of 71 participants from 21 countries.

Table I. Distribution of the study sample according to the cultural clusters

\begin{tabular}{|c|c|c|c|}
\hline $\begin{array}{l}\text { Cultural } \\
\text { clusters }\end{array}$ & Countries (n) & $\boldsymbol{F}$ & $\%$ \\
\hline Middle East & $\begin{array}{l}\text { Turkey (24), Palestine (6), Syria (32), Iran (12), Egypt (7), Yemen (1), Iraq (5), Morocco } \\
\text { (3), Algeria (1) }\end{array}$ & 91 & 47 \\
\hline $\begin{array}{l}\text { Sub-Saharan } \\
\text { African }\end{array}$ & $\begin{array}{l}\text { Ghana (5), Guinea (5), Tanzania (3), Somalia (14), Mali (4), Ethiopia (6), Sudan (12), } \\
\text { Burkina Faso (2), S. Africa R. (1), Kenya (1), Nigeria (3), Gambia (2), Comoros (1), } \\
\text { Congo (4), Cameroon (3), Zambia (1), Rwanda (1), Zimbabwe (1), Gabon (1), Malawi } \\
\text { (1) }\end{array}$ & 71 & 37 \\
\hline Central Asian & Azerbaijan (9), Turkmenistan (11), Kazakhstan (5), Kyrgyzstan (4), Uzbekistan (2) & 31 & 16 \\
\hline TOTAL & Total from 35 countries & 193 & 100 \\
\hline
\end{tabular}

\subsection{Measures and analaysis}


A questionnaire form was used as a data collection tool. In the first part of the questionnaire, Version 3 of the Kolb Learning Styles Inventory developed by David Kolb was applied, and the LSI Version 3.0 was offered to students in both Turkish and English languages. In the second part of this form, there was a demographic survey questioning gender, age, nationality, ethnicity, and which country, city, or state they came from. During the data collection, firstly, the students were interviewed face to face and were explained the purpose of the study and how to code the questionnaire. Then, according to their preference, one of the English or Turkish forms of the questionnaire was given to the respondents.

The designed KLSI aimed to measure the extent of individuals' learning styles that were determined based on Kolb's experiential learning theory. KLSI had a forced-choice format, and this format was for ordering an individual's relative choice preferences among the four modes of the learning cycle. In all versions of the LSI, there was the same short questionnaire format including 9 items for LSI 1 and 12 items for subsequent versions, and in this questionnaire, the respondents were asked to make four-sentence endings corresponding to the four learning modes in order, which are Concrete Experience (e.g., experiencing), Reflective Observation (reflecting), Abstract Conceptualization (thinking), and Active Experimentation (doing)" (Kolb, \& Kolb, 2005, p.10). The KLSI was used to evaluate six variables, four primary scores measuring an individual's relative emphasis on the four learning style types, namely Concrete Experience (CE), Reflective Observation (RO), and Abstract Conceptualization (AC). Also, to measure an individual's preference for abstractness over concreteness (AC-CE) and action over reflection (AE-RO) was benefitted from two combination scores.

The four basic learning style types - accommodating, diverging, assimilating, and converging - are determined through a division of the AC-CE and AE-RO scores at the 50th percentile of the total norm group and display of them on the Learning Style Type Grid (Kolb 1999, p. 6). While the cut point for the AC-CE scale was +7 , the cut point for the AE-RO scale was +6 . While the Accommodating type was showed by an AC-CE raw score $<=7$ and an $\mathrm{AE}-\mathrm{RO}$ score $>=7$, the Diverging type was shown by $\mathrm{AC}$ $\mathrm{CE}<=7$ and $\mathrm{AE}-\mathrm{RO}<=6$, and the Converging type by $\mathrm{AC}-\mathrm{CE}>=8$ and $\mathrm{AE}-\mathrm{RO}>=7$, and also the Assimilating type by $\mathrm{AC}-\mathrm{CE}>=8$ and $A E-R O<=6$. The point obtained by the AE-RO process was placed on the horizontal axis (information processing dimension) on this grid, and on the other hand, the point obtained by the AC-CE process was on the vertical axis (information perception dimension), and so, the learning style of the individual could be seen from the intersecting region (Gencel, 2006). In a recent theoretical and empirical study, it is notable that the main four learning styles may be improved by making small changes to display nine distinct styles (Eickmann, Kolb \& Kolb, 2004; Kolb \& Kolb 2005; Mainemelis, Boyatzis \& Kolb 2002). Instead of dividing the grid at the 50th percentiles of the LSI normative distributions for AC-CE and AE-RO, the nine styles are defined by dividing the two normative distributions into thirds. Table II shows these cut-points of the 9 learning styles of Kolb defined in KÖSE 3.2 (Kolb and Kolb, 2013, p. 46).

Table II. The score ranges for Kolb's 9 learning styles

\begin{tabular}{|c|c|c|c|}
\hline Kolb's 9 Learning Styles & $\begin{array}{l}\text { Information } \\
\text { Dimension }\end{array}$ & Perception & Information Processing Dimension \\
\hline Initiating & $A C-C E<2$ & & $\mathrm{AE}-\mathrm{RO}>11$ \\
\hline Experiencing & $A C-C E<2$ & & $A E-R O>0 \&<12$ \\
\hline Imagining & $A C-C E<2$ & & $A E-R O<1$ \\
\hline Reflecting & AC-CE $>1 \&<13$ & & $A E-R O<1$ \\
\hline Analysing & $A C-C E>12$ & & $A E-R O<1$ \\
\hline
\end{tabular}


Thinking

Deciding

Acting

Balancing
AC-CE $>12$

$\mathrm{AC}-\mathrm{CE}>12$

AC-CE $>1 \&<13$

$A C-C E>1 \&<13$
$\mathrm{AE}-\mathrm{RO}>0 \&<12$

$\mathrm{AE}-\mathrm{RO}>11$

AE-RO > 11

$\mathrm{AE}-\mathrm{RO}>0 \&<12$

The data were analysed by using descriptive analysis and that of variance procedures employing the Statistical Package for the Social Sciences (SPSS) Version 15., based on the research questions. The score for each axis was calculated firstly by summing up the scores of the learning mod in the respective category followed by mean scores on each quadrant of learning styles. The mean values were used for conclusions. Kolb's learning styles are nominal values specified with reference ranges, so the Chi-square analysis $\left(X^{2}\right)$ was used to compare the learning styles of the cultural groups. In contrast, the scores of $C E, A C, A E, R O$, and $A C-C E$, $\mathrm{AE}-\mathrm{RO}$ are not nominal values, and these scores showed normal distribution. For this, the one-way analysis of variance (ANOVA) was used to determine the significant difference between the three cultural clusters on these scores. The Scheffe analysis, which is one of the Post Hoc Tests, was used to explain among which groups this difference was.

\section{Results}

\subsection{Kolb Learning Styles According to Cultural Clusters}

Table 3 summarizes cross-national differences in Kolb's four learning styles by reporting percentages of each culture in each quadrant. For the total sample, dominant learning styles were determined as diverging (33\%), converging (26\%), assimilating (22\%), and accommodating (18\%), respectively. A majority of the Middle East (33\%) and Sub-Saharan African (38\%) clusters were found in the diverging quadrant, while a majority of the Central Asian cluster was found in converging (36\%) and accommodating (29\%) quadrants. In other words, more than half of the students in the Middle East and Sub-Saharan African clusters were in the west quadrant, whereas two-thirds of students in the Central Asian cluster were in the east quadrant. However, the chi-square analysis had explained that there was no significant difference concerning four learning styles $\left[X^{2}=6.76\right.$, and $\left.p>0.05\right]$. The students from the Middle East and Sub-Saharan African clusters were closer together than their Central Asian counterparts

Table III. The four learning styles and cultural clusters

\section{Concrete Experience (CE)}

"Feeling"

\begin{tabular}{|c|c|c|c|c|c|c|c|c|}
\hline \multirow{6}{*}{ 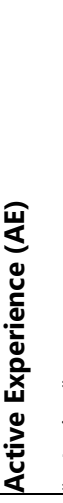 } & & \multicolumn{3}{|c|}{ Accommodating } & \multicolumn{3}{|l|}{ Diverging } & \multirow{6}{*}{ 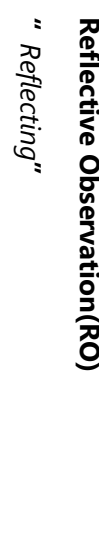 } \\
\hline & & Group & N & $\%$ & Group & $\mathrm{n}$ & $\%$ & \\
\hline & & Middle East & 15 & 17 & Middle East & 30 & 33 & \\
\hline & & $\begin{array}{l}\text { Sub-Saharan } \\
\text { African }\end{array}$ & 11 & 15 & $\begin{array}{l}\text { Sub-Saharan } \\
\text { African }\end{array}$ & 27 & 38 & \\
\hline & in & Central Asian & 9 & 29 & Central Asian & 7 & 23 & \\
\hline & $\ddot{\tau}$ & Total & 35 & 19 & Total & 64 & 33 & \\
\hline
\end{tabular}




\begin{tabular}{|c|c|c|c|c|c|}
\hline \multicolumn{3}{|l|}{ Converging } & \multicolumn{3}{|l|}{ Assimilating } \\
\hline Group & $\mathrm{N}$ & $\%$ & Group & $\mathrm{n}$ & $\%$ \\
\hline Middle East & 23 & 25 & Middle East & 23 & 25 \\
\hline $\begin{array}{l}\text { Sub-Saharan } \\
\text { African }\end{array}$ & 17 & 24 & $\begin{array}{l}\text { Sub-Saharan } \\
\text { African }\end{array}$ & 16 & 23 \\
\hline Central Asian & 11 & 36 & Central Asian & 4 & 13 \\
\hline Total & 51 & 26 & Total & 43 & 22 \\
\hline
\end{tabular}

\section{Abstract Conceptualisation (AC)}

"Thinking"

Table IV summarizes cross-national differences in Kolb's four learning styles by reporting percentages of each culture in each quadrant. For the total sample, dominant learning styles were determined as diverging (33\%), converging (26\%), assimilating (22\%), and accommodating (18\%), respectively. A majority of the Middle East (33\%) and Sub-Saharan African (\%38) clusters were found in the diverging quadrant, while a majority of the Central Asian cluster was found in converging (36\%) and accommodating (29\%) quadrants. In other words, more than half of students in the Middle East and Sub-Saharan African clusters were in the west quadrant, whereas two-thirds of students in the Central Asian cluster were in the east quadrant. Also, in all quadrants, the students from the Middle East and Sub-Saharan African clusters were closer together than their Central Asian counterparts. However, the chi-square analysis had explained that there was no significant difference concerning Kolb's four learning styles $[\chi 2=6,76$, and $p>0,05]$.

As seen in Table IV, all nine learning styles were determined in the sample. However, the dominant learning style of $20 \%$ of the participants was balancing. It was found that about half of the participants (45\%) preferred experiencing $(n=34 ; 18 \%)$, imagining $(n=31 ; 16 \%)$, reflecting $(n=23 ; 12 \%)$ learning styles. According to the Experiential Learning Theory model, individuals in these learning styles prefer concrete experiences in grasping to experience and reflective observation in transforming to experience. The thinking and analysing learning styles that prefer abstract conceptualization in grasping to experience, and the deciding learning style that prefers active experimentation in transforming to experience were $13 \%$ of the total sample. Among the three culture clusters, balancing compensatory in the Middle East group ( $n=18 ; 19 \%$ ), experiencing in the Sub-Saharan African group $(n=18 ; 25 \%)$, and acting $(n=8 ; 26 \%)$ and balancing $(n=7 ; 23 \%)$ in Central Asian group were the dominant learning styles. Those who prefer the thinking learning style in the Sub-Saharan African group, and reflecting, analysing and deciding learning styles in Central Asia were represented with only one student each. The thinking learning style in the Central Asian group and initiating learning style in the Sub-Saharan African group were not detected. The chi-square analysis results had shown that there was a significant difference in learning styles among the three cultural groups $\left[\chi 2=26,911, p=0,04^{*}\right]$. 
Table IV. The nine learning styles and cultural clusters

Concrete Experience

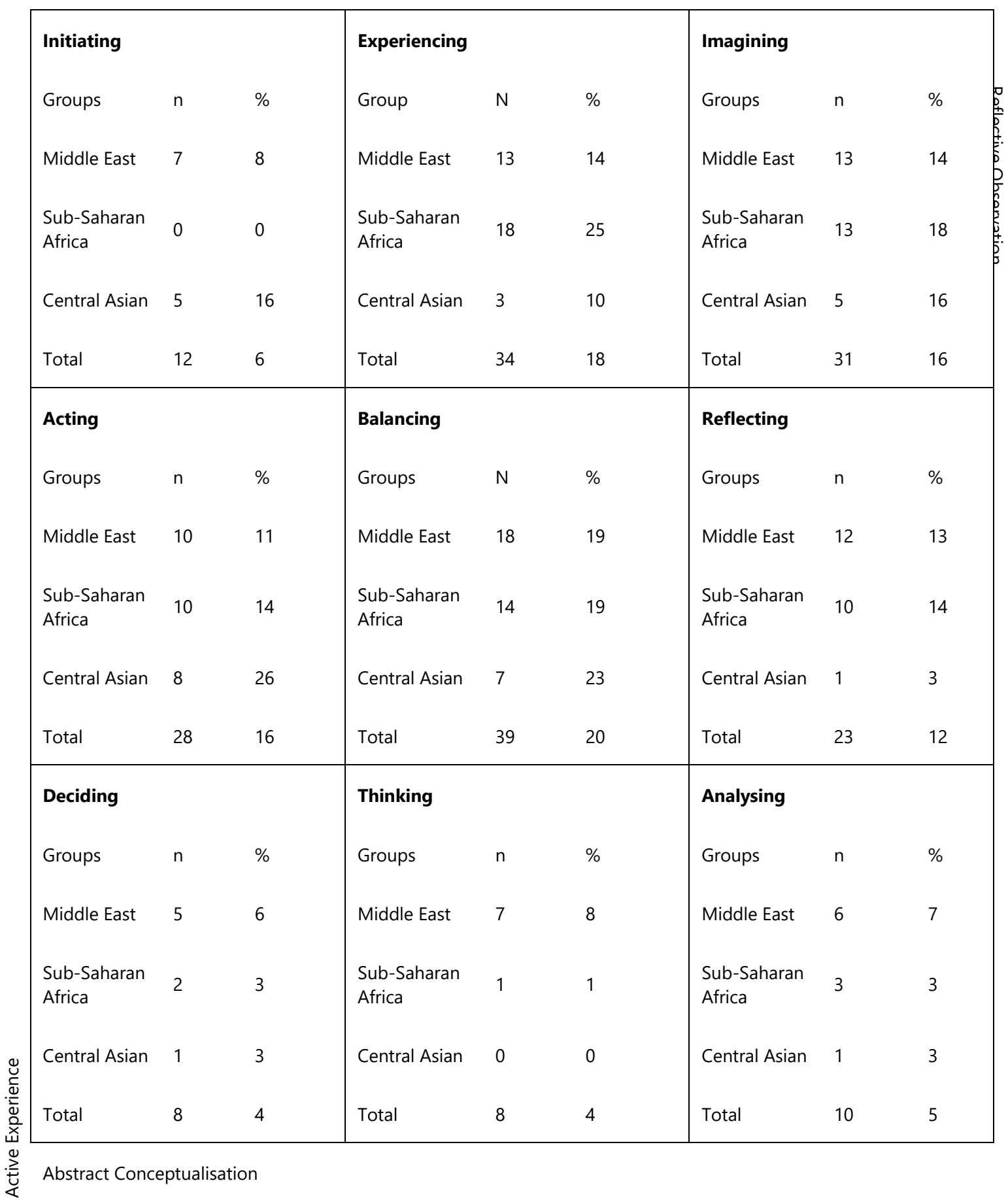




\section{2. The findings related to the four phases of the learning cycle (CE, RO, AC, AE)}

"The ELT model portrays two dialectically related modes of grasping experience - Concrete Experience (CE) and Abstract Conceptualization (AC)- and two dialectically related modes of transforming experience -Reflective Observation (RO) and Active Experimentation (AE)" (A. Kolb, \& D. Kolb, 2011, p. 44). Besides learning styles, the four stages (CE, $R O, A C, A E)$ of the learning cycle defined in the Experiential Learning Theory (ELT) model provide a practical tool to compare not only individual, but also collective cultural learning styles (Barmeyer, 2004). As seen in Table V, the mean CE scores of the total sample were 27.64, and the means of cultural clusters were respectively Sub-Saharan African $(\bar{X}=28.76)$, Central Asian $(\bar{X}=27,64)$, and the Middle East $(\bar{X}=26.65)$. According to the ANOVA test results, the difference between the scores of $C E$ of the groups was statistically significant $(F=0.65$, and $p<0.05)$. The Scheffe analysis result of Post Hoc had explained that this difference was between Sub-Saharan African and Middle Eastern groups. In other words, the high CE score in the Sub-Saharan Africa cluster represents a receptive, experiencebased approach to learning, relies on feeling-based judgments, and tends to be people-oriented. They prefer learning environments where they can express themselves, such as in discussions (Barmeyer, 2004).

Table V. The ANOVA test results of concrete experience (CE) scores on the cultural clusters

\begin{tabular}{|c|c|c|c|c|c|c|c|c|c|}
\hline Group & $N$ & $\bar{X}$ & $S d$ & & $\begin{array}{l}\text { Sum } \\
\text { Squares }\end{array}$ & ${ }^{\text {of }} d f$ & $\begin{array}{l}\text { Mean } \\
\text { Square }\end{array}$ & $F$ & $P$ \\
\hline Middle East & 91 & 26.75 & 5.28 & Between groups & s 161.7 & 2 & 80.8 & \multirow{3}{*}{3.12} & \multirow{3}{*}{$0.04^{x}$} \\
\hline Sub- Saharan African & 71 & 28.76 & 5.08 & Within groups & 4918.8 & 190 & 25.8 & & \\
\hline Central Asian & 31 & 27.64 & 4.44 & Total & 5080.6 & 192 & & & \\
\hline Total & 193 & 27.64 & 5.14 & & & & & & \\
\hline
\end{tabular}

In grasping to experience, the total mean score of AC versus CE was 31.08, and the group means were respectively the Middle East $(\bar{X}=31,55)$, Central Asian $(\bar{X}=30,65)$, and Sub- Saharan African $(\bar{X}=30,68)$ (see Table VI). However, the ANOVA test results had shown that there was no significant difference among $C E$ scores of the three culture groups $(F=0.76$ and $p>0.05)$. A high score on $\mathrm{AC}$ represents an analytical and conceptual approach to learning, relies on logical thinking and rational evaluation tends to be more oriented towards objects and symbols and less toward other people. They learn best by thinking in neutral learning situations (Barmeyer, 2004; Kolb, 1984; Kolb \& Kolb, 2006).

Table VI. The ANOVA test results of abstract conceptualization (AC) scores on the cultural clusters

\begin{tabular}{|c|c|c|c|c|c|c|c|c|c|}
\hline Group & $N$ & $\bar{x}$ & Sd & & $\begin{array}{l}\text { Sum } \\
\text { Squares }\end{array}$ & ${ }^{\text {of }} d f$ & $\begin{array}{l}\text { Mean } \\
\text { Square }\end{array}$ & $F$ & $P$ \\
\hline Middle East & 91 & 31.55 & 4.89 & $\begin{array}{l}\text { Between } \\
\text { groups }\end{array}$ & 38.3 & 2 & 19.1 & 0.76 & 0.47 \\
\hline Sub- Saharan African & & 30.65 & 5.23 & Within groups & 4791.4 & 190 & 25.2 & & \\
\hline Central Asian & 31 & 30.68 & 4.88 & Total & 4829.8 & 192 & & & \\
\hline Total & 193 & 31.08 & 5.02 & & & & & & \\
\hline
\end{tabular}


The highest mean of RO scores, which are one of two dialectically related modes of transforming experience (Reflective Observation - RO, and Active Experimentation - AE), was detected in the Sub-Saharan Africa group $(\bar{X}=29,35)$, and the lowest one in the Central Asian group ( $\bar{X}=26.96)$. A high score on RO indicates a tentative and reflective approach to learning, relies heavily on careful observation and a preference learning situation such as lectures (Barmeyer, 2004). As seen in Table VII, the ANOVA test result had shown that there was no statistically significant difference among the groups $(F=1.82$ and $p>0.05)$.

Table VII. The ANOVA test results of reflective observation (RO) scores according to the culture group variable.

\begin{tabular}{|c|c|c|c|c|c|c|c|c|c|}
\hline Group & $N$ & $\bar{X}$ & $S d$ & & $\begin{array}{l}\text { Sum } \\
\text { Squares }\end{array}$ & ${ }^{\circ f} d f$ & $\begin{array}{l}\text { Mean } \\
\text { Square }\end{array}$ & $F$ & $P$ \\
\hline Middle East & 91 & 28.71 & 5.60 & Between groups & 123.04 & 2 & 61.52 & \multirow{3}{*}{1.82} & \multirow{3}{*}{0.17} \\
\hline Sub- Saharan & n 71 & 29.35 & 5.89 & Within groups & 6431.74 & 190 & \multirow[t]{2}{*}{33.85} & & \\
\hline Central Asian & 31 & 26.96 & 6.24 & Total & 6554.78 & 192 & & & \\
\hline Total & 193 & 28.66 & 5.84 & & & & & & \\
\hline
\end{tabular}

The ANOVA test results regarding the scores of AE which are the other way of processing information are shown in Table VIII. The difference between the Central Asian group $(\bar{X}=34.68 ; s d=5.41)$ with the highest $A E$ average and the African group $(\bar{X}=31.25$; $s d=5.40)$ with the lowest $A E$ one was found to be statistically significant $(F=4.32$ and $p<0.05)$. The African group prefers the way of acting learning more than other groups in the perception of information.

Table VIII. The ANOVA test results of active experience (AE) scores according to the culture group variable.

\begin{tabular}{|c|c|c|c|c|c|c|c|c|c|}
\hline Group & $N$ & $\bar{X}$ & $S d$ & & Sum of & $d f$ & $\begin{array}{l}\text { Mean } \\
\text { Square }\end{array}$ & $F$ & $P$ \\
\hline Middle East & 91 & 32.89 & 5.78 & $\begin{array}{l}\text { Among } \\
\text { groups }\end{array}$ & the ${ }_{270.04}$ & 2 & 135.0 & \multirow[t]{3}{*}{4.32} & \multirow[t]{2}{*}{$0.01^{*}$} \\
\hline Sub- Saharan African & & 31.25 & 5.40 & In-group & 5937.1 & 190 & 31.2 & & \\
\hline Central Asian & 31 & 34.68 & 5.41 & Total & 6207.1 & 192 & & & \\
\hline Total & 193 & 32.58 & 5.69 & & & & & & \\
\hline
\end{tabular}

\subsection{The findings for abstract conceptualization over concrete experience (AC-CE) versus active experimentation over reflective observation (AE-RO)}

Based on the participants' preference for abstract conceptualization over concrete experience (AC-CE) to grasp an experience while learning, the analysis results are summarized in Table IX. The ANOVA test results explain that there is no significant difference among the groups $(\mathrm{F}=2.47$ and $\mathrm{p}>0.05)$. 
Table IX. The ANOVA test results for abstract conceptualization over concrete experience (AC-CE)

\begin{tabular}{lcccccccc}
\hline Group & $N$ & $\bar{X}$ & Sd & & Sum of Squares $d f$ & $\begin{array}{l}\text { Mean } \\
\text { Square }\end{array}$ & $F$ \\
\hline Middle East & 91 & 4.80 & 8.66 & Between groups 346.0 & 2 & 173 \\
Sub- Saharan African71 & 1.89 & 8.34 & Within groups & 132.5 & 190 & 69.9 & 2.47 & 0.09 \\
Central Asian & 31 & 3.00 & 7.45 & Total & 13633.5 & 192 & & \\
Total & 193 & 3.44 & 8.43 & & & & \\
\hline
\end{tabular}

Table $X$ shows the findings on active experimentation over reflective observation to transform an experience while learning. The mean of the whole sample was 3.91 ( $s d=10.04)$, and the group values were respectively the Central Asian $(\bar{X}=7.71 ; s d=10.25)$, the Middle East $(\bar{X}=4.18 ; s d=10.06)$ and Sub-Saharan African $(\bar{X}=1.90 ; s d=9.53)$. According to ANOVA results, there was a significant difference among cultural groups $(F=3.78 ; p<0.05)$, and the results of Post Hoc Scheffe analysis had explained that this difference was between the Central Asian and Sub-Saharan African groups.

Table X. The ANOVA test results for active experimentation over reflective observation (AE-RO)

\begin{tabular}{|c|c|c|c|c|c|c|c|c|c|}
\hline Group & $N$ & $\bar{X}$ & $S d$ & & Sum of Squares & $d f$ & $\begin{array}{l}\text { Mean } \\
\text { Square }\end{array}$ & $F$ & $P$ \\
\hline Middle East & 91 & 4.18 & 10.06 & Between groups & 740.44 & 2 & 370.22 & & \\
\hline Sub- Saharan African & 71 & 1.90 & 9.53 & Within groups & 18615.88 & 190 & 97.99 & 3.78 & $0.03^{*}$ \\
\hline Central Asian & 31 & 7.71 & 10.25 & Total & 19356.32 & 192 & & & \\
\hline Total & 193 & 3.91 & 10.04 & & & & & & \\
\hline
\end{tabular}

\section{Discussion}

The results of the research revealed that there was no significant difference among the cultural clusters, based on Kolb's four learning styles, and on the other hand, the difference among the cultural clusters was significant according to Kolb's new nine learning style classification. Besides, a statistically significant difference was found between the Middle East and Sub-Saharan African clusters in terms of the scores of concrete experience (CE), which is one of the two dialectical modes of grasping experience described in Kolb's ELT model.

These high CE scores of the Sub-Saharan African cluster may mean a preference for personal interaction with people and a more intuitive approach to problems and situations. Significant differences were detected between Sub-Saharan African and Central Asian clusters in terms of the combination AE-RO scores with active experimentation (AE), which is one of the modes of transforming experience in the ELT model. According to the ELT model, this result implies that students in the Sub-Saharan African cluster were mostly preferred "feeling" and "experiencing" learning ways, whereas, "doing" learning way of students in the Central Asian cluster was more dominant than other clusters. These results were consistent with some of the findings of intercultural studies on Kolb's learning styles (for example; Auyeung \& Sands,1996; Barmeyer, 2004; Joy, \& Kolb, 2009; Holtbrügge \& Mohr, 2010). 
Considering the findings of previous studies focusing on the effect of culture on learning styles, it does not seem possible to generalize the representation of certain cultures with certain learning styles. However, the results of the studies focused on the relationship between culture and learning style suggest that culture is a variable that should be taken into account in studies related to learning. For example, in a meta-analysis of Yamazaki (2005), where studies on the relationship between learning styles and culture were examined, the number of the studies examined was not sufficient to fully understand the relationship between cultural differences and learning styles; however, it might shed light on which culture was associated with which learning ability or style.

Furthermore, it was understood that intercultural studies related to learning styles were mostly compared by selecting countries from different cultural clusters. For example, in the study of Barmeyer (2004) the learning styles of university students who were French, German, and Canadian (Quebec) were compared. The results of that study had shown that French and Quebec students had significantly higher CE scores while German ones had significantly higher AE ones. Besides, the researcher reported that the results of French students and French-speaking Quebec students were generally very close to each other. The study of Joy and Kolb (2009) was conducted with 533 participants from the United States of America (USA), Italy, Germany, Poland, Brazil, India, and Singapore. The results of this study showed that culture had a significant influence on the choice between abstract conceptualization and concrete experience, and also had a marginal effect on the choice between active experimentation and reflective observation. Instead, it was determined that culture was of partial importance in the combination of AE-RO scores. The study of Holtbrügge and Mohr (2010) was conducted with 939 students from 74 different countries studying at various universities in Germany, England, the USA, Russia, Holland, Poland, China, and the United Arab Emirates. This study had important findings that support the argument that those with different cultural backgrounds may have different learning styles.

It is noteworthy that the samples of some intercultural studies on learning styles are represented by specific areas of expertise. In one of such studies, Auyeung and Sands (1996) compared the learning styles of students studying in the field of accounting of two universities in about the same period in China and Australia. Findings of this study used KLSI as a data collection tool were shown that, based on learning styles, learning modes ( $C E, R O, A C, A E)$, and the combination scores $(A C-C E, A E-R O)$, there was no significant difference in the comparison within the country, while these differences were statistically significant in the comparison between countries. The researchers reported that Australian students were mostly represented by accommodating learning style while Chinese students were represented mostly by assimilating learning style. In another study, the learning styles of undergraduates studying in the field of accounting in Japan, Austria, and Belgium were compared. In that study, it was determined that Japanese students mostly preferred diverging learning style while the Austrian and Belgian groups mostly assimilating learning style. Also, the findings of this study showed that the AE-RO scores of the Japanese group were significantly lower than the other two groups (Boland et. al., 2011). Besides, in a study carried out with undergraduate students studying in the field of business administration in the USA, Korea, and India, it was determined that there were intercultural differences in learning styles (Jaju et.al., 2002). The findings of this study had revealed that the USA group preferred RO and CE (diverging) learning modes, the Indian group - AE and AC (converging) ones, and Korean students - RO and AC (assimilating) ones. In another comparative study on the learning styles of marketing undergraduate students from Bulgaria and the USA (Budeva et al., 2012), attention was drawn to intercultural differences. Furthermore, in intercultural studies conducted with adults from certain professions rather than students, it was reported that there were differences in learning styles. The study of Hoppe (1990) was carried out by reaching a large sample $(\mathrm{N}=1544)$ consisting of adults with different demographics features from 19 countries, including Turkey between 1983 and 1984 years. The findings of that study in which the first version of KLSI with 9 items was used revealed that there was a strong relationship between learning styles and some of the cultural dimensions. Respondents in another study were French and American executives working in multinational companies (Grossi, 2013). In this study, it was 
reported that American executives were more prone to be converging and accommodating while French executives - to be assimilating and diverging.

The results of the studies on learning styles in higher education reveal that the effect of some demographic variables, especially the area of expertise was more than the effect of culture (Joy \& Kolb, 2009). However, the results of intercultural studies on learning styles suggest that the cultural background may be an important determinant of the preferred learning styles because each individual has a particular cultural background and experience. This possibility may require re-interrogation of the multicultural education systems and their potentials which became widespread in Europe especially with the Bologna Declaration. If individuals from different cultural backgrounds have preferences for different learning styles, a single teaching model may be unlikely to help students obtain the learning outcomes required for the field (Holtbrügge \& Mohr, 2010). Besides, although there are many problems in intercultural education, the diversity of learning styles and study strategies may be a valuable source of cultural synergy by leading to a variety of problem-solving ways and more different solutions. It may be expected that understanding the learning style preferred by the person himself and others help also weaker areas to be understood in learning. This allows people to work on being more competent in areas where they find themselves weak or helps them to recognize the strengths that are useful in cross-cultural training and managing situations. Educators who know more about learning styles will direct the education methods in line with the wishes and learning preferences that may differ according to the learning styles of the respondents. Therefore, at the beginning of an education session, the analysis of the students' learning styles can be very useful and can contribute to real improvement as a result of the education (Barmeyer, 2004).

Taking into account that there was no study on the learning styles of foreign students studying in Turkey, the study may be considered a contribution to the literature but still had some limitations. As stated in the introduction part, in Turkey, foreign students are studying in different universities, who are from over 140 different countries, and the number of these students has been increasing from year to year. Studies with larger samples and with the representation of more different cultural clusters are needed to identify the learning ways of different cultural clusters and to understand whether there is an intercultural difference in learning. Foreign students in Turkey come from African and Asian countries, especially from the neighboring countries and Central Asian Turkish Republic countries. Considering that these countries have not been sufficiently represented in the sample of previous studies on intercultural learning styles, it is clear that future studies on multicultural education in Turkey have the potential to remedy this deficiency in the literature.

\section{Ethics Committee Approval Information}

Conducting this study was unanimously approved at the meeting, dated 28.02.2017, of the Ethics Committee of Social and Human Sciences in Ondokuz Mayıs University (Decision No: 2017/23). 


\section{References}

Abramson, N.R., Keating, R.J., \& Lane, H. W. (1996). Cross-national cognitive process differences: A comparison of Canadian, American, and Japanese managers. MIR: Management International Review, 36(2),123-147.

Allinson, C. W. \& Hayes, J. (2000). Cross-national differences in cognitive style: implications for management. International Journal of Human Resource Management, 11(1), 161-170.

Auyeung, P. \& Sands, J. (1996). A cross-cultural study of the learning style of accounting students. Accounting \& Finance, 36(2): 261-274.

Barmeyer, C.I. (2004). Learning styles and their impact on cross-cultural training: An international comparison in France, Germany, and Quebec. International Journal of Intercultural Relations, 28(6), 577-594.

Berberoglu, G. \& Hei, L. M. (2003). A comparison of university students' approaches to learning across Taiwan and Turkey. International Journal of Testing, 3(2), 173-187.

Boland, G., Sugahara, S., Opdecam, E., \& Everaert, P. (2011). The impact of cultural factors on students' learning style preferences. Asian Review of Accounting, 19(3), 243-265

Budeva, D., Kehaiova, M., \& Petkus, E. (2015). Nationality as a Determinant of Learning Styles Preferences: Comparing Students from Bulgaria and the USA. E-Journal of Business Education and Scholarship of Teaching, 9(1), 97-106.

Cagiltay, K., \& Bichelmeyer, B. (2000). Differences in Learning Styles in Different Cultures: A Qualitative Study. Paper presented at the Annual Meeting of the American Educational Research Association, New Orleans. Retrieved from https://pdfs.semanticscholar.org/9445/b508d4bb946b20d07afbc11c9930dcf7ca33.pdf"

Çelikler, D. (2020). A comparison on the learning styles of chemistry students and chemistry education students in universities in Turkey. African Educational Research Journal, 8(4), 841-848.

Dunn, R., Dunn, K., \& Price, G. (1985). Manual: Learning style inventory. Lawrence, KS: Price Systems.

Dunn, R., Gemake, J., Jalali, F., \& Zenhausern, R. (1990). Cross-cultural differences in learning styles of elementary-age students from four ethnic backgrounds. Journal of Multicultural Counseling and Development, 18(2), 68-93.

Eickmann, P., Kolb, A., \& Kolb, D. A. (2004). Designing learning. Paper presented at the Managing as Designing: Creating a New Vocabulary for Management Education and Research, Weatherhead School of Management, Case Western Reserve University, Cleveland, Ohio. June $14 \quad$ - $\quad 15, \quad 2002$, Retrived from https://citeseerx.ist.psu.edu/viewdoc/download?doi=10.1.1.187.509\&rep=rep1\&type=pdf

Furnham, A. \& Stringfield, P. (1993). Personality and work performance: Myers-Briggs Type Indicator correlates of managerial performance in two cultures. Personality and Individual Differences, 14(1), 145-153.

Gencel, İ.E. (2007). Kolb'un Deneyimsel Öğrenme Kuramına dayalı Öğrenme Stilleri Envanteri-III'ü Türkçeye uyarlama çalışması [Turkish adaptation study of Learning Styles Inventory-III based on Kolb's Experiential Learning Theory]. Dokuz Eylül Üniversitesi Sosyal Bilimler Enstitüsü Dergisi, 9(2), 120-139.

Given, B.K. (1996). Learning styles: a synthesized model. Journal of Accelerative Learning and Teaching, 21, 9-42. 
Grossi, R. (2013). Different preferences in learning between American and French learners in a multinational corporate setting. Unpublished Thesis. Cypress, CA: Trident University International. Retrieved from https://search.proquest.com/docview/1460760347?accountid=16701

Gündüz, N., \& Özcan, D. (2010). Learning styles of students from different cultures and studying in Near East University. ProcediaSocial and Behavioral Sciences. 9, 5-10.

Healey, M., Kneale, P., \& Bradbeer, J. with other members of the INLT Learning Styles and Concepts Group. (2005). Learning styles among geography undergraduates: an international comparison. AREA, 37(1), 30-42.

Heffernan, T., Morrison, M., Basu, P., \& Sweeney, A. (2010). Cultural differences, learning styles, and transnational education. Journal of Higher Education Policy and Management, 32(1), 27-39.

Holtbrügge, D. \& Mohr, A. T. (2010). Cultural determinants of learning style preferences. Academy of Management Learning \& Education, 9(4), 622-637.

Hoppe, M.H. (1990). A comparative study of country elites: International differences in work-related values and learning and their implications for management training and development. Chapel Hill, NC: The University of North Carolina. Retrieved from https://search.proquest.com/docview/303910413?accountid=16701"

House, R.J., Hanges, P.J., Javidan, M., Dorfman, P.W., \& Gupta, V. (2004). Culture, leadership, and organizations: The GLOBE study of 62 societies. London: Sage Publications.

Jaju, A., Kwak, H., \& Zinkhan, G. M. (2002). Learning styles of undergraduate business students: A cross-cultural comparison between the US, India, and Korea. Marketing Education Review, 12(2), 49-60. DOI: https://doi.org/10.1080/10528008.2002.11488787.

Joy, S. \& Kolb, D. A. (2009). Are there cultural differences in learning styles? International Journal of Intercultural Relations, 33(1), 69-85.

Kolb, D. A. (1999). Learning style inventory: Version 3. Boston: Hay/McBer Training Resources Group.

Kolb, D. A. (1984). Experiential Learning. Englewood Cliffs, NJ: Prentice-Hall.

Kolb, A.Y., \& Kolb, D. A. (2013). Learning Style Inventory Version 3.1 \& 3.2 technical specifications. Boston: Hay Resources Direct.

Kolb, A., \& Kolb, D. (2011). Experiential Learning Theory: A Dynamic, Holistic Approach to Management Learning, Education and Development. In S. J. Armstrong \& C. Fukami (Eds.), The SAGE Handbook of Management Learning, Education and Development (pp. 42-68). London: SAGE.

Kolb, A.Y., \& Kolb, D.A. (2006). Learning styles and learning spaces: A review of the multidisciplinary application of experiential learning theory in higher education. In R. R. Sims \& S. J. Sims (Eds.), Learning Styles and Learning: A Key to Meeting the Accountability Demands in Education (pp. 45-91). New York: Nova Science Publishers.

Kolb, A.Y., \& Kolb, D.A. (2005). The Kolb learning style inventory-version 3.12005 technical specifications. Boston, MA.: Hay Resource Direct.

Kutay, H. (2006). A comparative study about learning styles preferences of two cultures. Doctorate dissertation. Columbus, $\mathrm{OH}$ : The

Ohio State University. Retrieved from
https://etd.ohiolink.edu/apexprod/rws_olink/r/1501/10?p10_etd_subid=64603\&clear=10 
Maldonado-Torres, S. E. (2011). Differences in learning styles of Dominican and Puerto Rican students: We are Latinos from the Caribbean; our first language is Spanish, however; our learning preferences are different. Journal of Hispanic Higher Education, 10(3), 226-236.

Mainemelis, C., Boyatzis, R. E., \& Kolb, D. A. (2002). Learning styles and adaptive flexibility: Testing experiential learning theory. Management Learning, 33(1), 5-33.

Marambe, K. N., Vermunt, J. D., \& Boshuizen, H. P. (2012). A cross-cultural comparison of student learning patterns in higher education. Higher Education, 64(3), 299-316.

Martínez-Fernández, J. R., \& Vermunt, J. D. (2015). A cross-cultural analysis of the patterns of learning and academic performance of Spanish and Latin-American undergraduates. Studies in Higher Education, 40(2), 278-295.

Nisbett, R. (2004). The geography of thought: How Asians and Westerners think differently... and why. New York: Simon and Schuster.

Obralic, N., \& Akbarov, A. (2012). Student's preference on perceptual learning style. Acta Didactica Napocensia, 5(3), 31-42.

Özdemir, N. (2015). A comparative study regarding the learning styles of Turkish undergraduate geography students and their western counterparts. Firat Üniversitesi Sosyal Bilimler Dergisi, 25(1), 71-88.

Pokharel, T. (2013). Learning styles of international participants of executive development programmes. Sky Journal of Educational Research, 1(4), 32 - 47

Yamazaki, Y. (2005). Learning styles and typologies of cultural differences: A theoretical and empirical comparison. International Journal of Intercultural Relations, 29(5), 521-548.

Yamazaki, Y. \& Kayes, D. C. (2004). An experiential approach to cross-cultural learning: A review and integration of competencies for successful expatriate adaptation. Academy of Management Learning \& Education, 3(4), 362-379.

YÖBYS. (2020). Uyruğuna göre ögrenci sayıları raporu [Report on the number of students by nationality]. Retrieved from: https://istatistik.yok.gov.tr/

Zualkernan, I. A., Allert, J., \& Qadah, G. Z. (2006). Learning styles of computer programming students: a Middle Eastern and American comparison. IEEE Transactions on Education, 49(4), 443-450. 